\title{
DUKUNGAN SOSIAL TENTANG EFIKASI DIRI MENYUSUI PADA IBU NIFAS
}

\author{
Agnes Julisca Cemara, Ratna Dewi, Wisuda Andeka Marleni \\ Politeknik Kesehatan Kementerian Kesehatan Bengkulu, Jurusan Kebidanan \\ Jalan Indragiri Nomor 3 Padang Harapan Bengkulu \\ agnes_julisca@yahoo.com
}

\begin{abstract}
Bengkulu City is the city with the lowest coverage of 9 districts / cities in Bengkulu Province in 2015 by 38\%. The success of breastfeeding can be increased in mothers who have high breastfeeding self-efficacy. One of the factors that influence breastfeeding self-efficacy is the existence of social support sourced from the family (husband), cadres, and health personnel (midwives). This study aims to determine the analysis of social support on breastfeeding self-efficacy of postpartum in the Working Area of PuskesmasLingkar. This research uses qualitative method with phenomenology approach. The subjects of the study were chosen by using purposive sampling technique consisting of 6 primary informants which is 3 postpartum mothers with high efficacy and 3 postpartum mothers with low efficacy and 6 secondary informants which is 2 midwives, 2 cadres and 2 husbands, each consisting of low and high efficacy. The results showed that social support in the form of family support (husband), cadres and health workers (midwives) affects self-efficacy of breastfeeding in postpartum. Forms of family support (husband) and health personnel (midwife) are informational, emotional, assessment and intrumental support. Forms of cadre support is just informational suppor. It is expected that health workers can provide a comprehensive extension of ASI to mother and family. Training of cadres also needs to be done to improve the role and task of cadres in improving the success of postpartum mother to breastfeed her baby exclusively.
\end{abstract}

Keywords: Exclusive Breast Milk, Social Support, Self-efficacy, Postpartum

\begin{abstract}
Abstrak: Kota Bengkulu merupakan kota dengan cakupan ASI terendah dari total 9 Kabupaten/Kota yang ada di Provinsi Bengkulu pada tahun 2015 sebesar 38\%. Keberhasilan menyusui dapat meningkat pada ibu yang memiliki efikasi diri menyusui tinggi. Salah satu faktor yang mempengaruhi efikasi diri menyusui yaitu adanya dukungan sosial yang bersumber dari keluarga (suami), kader,dan tenaga kesehatan (bidan). Penelitian ini bertujuan untuk mengetahui analisis dukungan social tentang efikasi diri menyusui pada ibu nifas di Wilayah Kerja Puskesmas Lingkar Barat. Penelitian ini mengguakan metode kualitatif dengan pendekatan fenomenologi. Subjek penelitian dipilih dengan menggunaan teknik purposive sampling yang terdiri dari informan 6 orang informan primer yaitu 3 ibu nifas dengan efikasi tinggi dan 3 ibu nifas dengan efikasi rendah dan 6 informan sekunder yaitu 2 bidan, 2 kader dan 2 suami yang masing-masing terdiri dari efikasi rendah dan tinggi. Hasil penelitian menunjukkan bahwa dukungan social berupa dukungan keluarga (suami), kader dan tenaga kesehatan (bidan) mempengaruhi efikasi diri menyusui pada ibu nifas. Bentuk dukunga nkeluarga (suami) dan tenaga kesehatan (bidan) berupa dukungan informasional, emosional, penilaian dan intrumental. Bentuk dukungan kader hanya dukungan informasional saja. Diharapkan petugas kesehatan dapat memberikan penyuluhan tentang ASI Eksklusif secara menyeluruh kepada ibu dan keluarga. Pelatihan kader juga perlu dilakukan untuk meningkatkan peran dan tugas kader dalam meningkatkan keberhasilan ibu nifas untuk menyusui bayinya secara ekslusif.
\end{abstract}

Kata Kunci: ASI Eksklusif, Dukungan Sosial, Efikasi diri, Ibu nifas 
Efikasi diri merupakan keyakinan seseorang mengenai kemampuan dirinya dalam melaksanakan tugas untuk mencapai suatu hasil tertentu (Gufron, 2010). Sedangkan, efikasi diri menyusui atau Breastfeeding Self Efficacy (BSE) merupakan keyakinan diri seorang ibu pada kemampuannya untuk menyusui atau memberikan ASI pada bayinya (Denis, 2010). Ibu yang memiliki efikasi diri menyusui tinggi maka keberhasilan menyusui akan meningkat begitu pula sebaliknya (Wardani, 2012).

Pakseresht et al (2017) melaporkan bahwa ibu post partum di Iran pada minggu pertama memiliki efikasi diri menyusui rendah sebanyak $53,71 \%$. Komalasari, dkk (2016) melaporkan bahwa tingkat efikasi diri menyusui ibu post partum di Indonesia yang dilakukan di Kota Bandung didapatkan bahwa lebih dari setengah respondenefikasi diri menyusui yang rendah.Feni (2017)mengatakanbahwa sebagian besar $(55,2 \%)$ ibu hamil di Kota Bengkulu memiliki nilai efikasi diri menyusui pada kategori rendah.Faktor yang mempengaruhi efikasi diri menyusui diantaranya adalah pengalaman melihat keberhasilan orang lain, kondisi fisik ibu, dukungan suami, pendidikan, paritas, dan pengalaman menyusui (Muaningsih, 2013; Febriana et al., 2014; Khoiriyah, 2014).

Dukungan sosial terhadap ibu menyusui merupakan perilaku yang mendukung pemberian ASI dari orang lain di dalam jaringan sosial yang dipercaya akan bermanfaat bagi dirinya. Dukungan sosial akan sangat dibutuhkan ibu untuk meningkatkan rasa percaya diri dalam menghadapi dan memecahkan masalah menyusui sehingga mencegah penghentian menyusui secara dini (Yusria, 2011). Sumber dukungan sosial yang kita terima dapat bersumber dari berbagai pihak bisa didapatkan dari keluarga dekat, pasangan (suami atau istri), teman dekat, teman kerja, sanak keluarga, dan teman sepergaulan.
Kota Bengkulu merupakan kota dengan cakupan ASI terendah dari total 9 Kabupaten/Kota yang ada di Provinsi Bengkulu pada tahun 2015 sebesar 38\% (Dinas Kesehatan Provinsi Bengkulu, 2015). Puskesmas Lingkar Barat merupakan puskesmas dengan cakupan ASI eksklusif terendah yaitu27,94\%.

Peneliti melakukan penelitian di Wilayah Puskesmas Lingkar Barat yang merupakan cakupan ASI terendah di Kota Bengkulu pada tahun 2016. Penelitian ini bertujuan untuk mengetahui analisis dukungan sosial tentang efikasi diri menyusui pada ibu nifas di Wilayah Kerja Puskesmas Lingkar Barat.

Survey awal yang dilakukan di Puskesmas Lingkar Barat pada 10 orang ibu menyusui dengan cara membagikan kuesioner mengenai efikasi diri, hasil kuesioner menunjukkan bahwa 3 dari ibu menyusui memiliki efikasi tinggi dan 7 orang memiliki efikasi rendah. Selanjutnya, hasil wawancara dengan ibu menyusui didapatkan bahwa tenaga kesehatan memberikan dukungan dalam bentuk melakukan IMD pada persalinan dan konseling mengenai pentingnya ASI eksklusif. Kemudian, dukungan kader hanya diberikan saat Posyandu dan dukungan keluarga terbatas dalam pemenuhan nutrisi ibu saja.

\section{BAHAN DAN CARA KERJA}

Penelitian ini menggunakan metode kualitatif dengan pendekatan fenomenologi yang bertujuan untuk menggali secaramen dalam mengenai dukungan social tentang efikasi diri menyusui pada ibu nifas di Wilayah Kerja Puskesmas Lingkar Barat.

Penentuan subjek atau informan penelitian dipilih dengan menggunakan teknik purposive sampling yaitu teknik dengan pertimbangan tertentu. Informan terdiri dari dua kategori yaitu informan primer dan subjek sekunder. Informan primer yaitu ibu nifas yang menyusui (6 orang) yang terdiri dari 3 ibu nifas dengan efikasi tinggi dan 3 ibu nifas dengan 
efikasi rendah. Informan sekunder merupakan triagulasi informan yang terdiri dari kader di lingkungan posyandu ibu nifas (2 orang) yaitu 1 orang kader ibu nifas dengan efikasi tinggi dan 1 orang kader ibu nifas dengan ibu efikasi rendah, bidan ( 2 orang) yaitu 1 orang bidan dari ibu nifas dengan efikasi tinggi dan 1 orang bidan dengan ibu nifas efikasi rendah dan suami (2 orang) yaitu 1 orang suami ibu nifas dengan efikasi tinggi dan 1 orang suami ibu nifas dengan efikasi rendah, sehingga total informan berjumlah 12 orang.

\section{HASIL}

\section{Dukungan Keluarga (suami)}

Hasil penelitian menujukkan bahwa informan yang memiliki efikasi rendah terhadap ASI Eksklusif tidak pernah mendapatkan informasi mengenai ASI Eksklusif. Sedangkan sebagian besar informan efikasi tinggi mendapatkan informasi mengenai ASI Eksklusif dari suaminya. Berikut kutipan wawancara dengan informan:

..."Kalo suami dak pernah ngasih tau cuma bidan tu lah..."

...(Kalo suami tidak pernah memberi tahu hanya bidan saja) (inf 2)

...” Ado pas hamil agak besak maren ado suami ngasih tau tentang ASI. Keceknyo baguslah ASI selain anak sehat kito lah ngirit, ngirit duit cak itu na. Iyo keceknyo daripada beli susu formula lemak disimpan untuk adek kelak..."

...(ada pas hamil sudah besar kemarin ada suami memberi tahu tentang ASI. Katanya baguslah ASI selain anak sehat kita hemat, hemat uang seperti itu. Iya katanya daripada beli susu formula lebih baik disimpan untuk anak nanti) (Inf 5)

Hasil penelitian menunjukkan bahwa sebagian kecil informan dengan efikasi rendah mendapatkan dukungan emosional dari suaminya sedangkan informan dengan efikasi tinggi semuanya mendapatkan dukungan emosional dari suaminya. Berikut kutipan wawancara oleh informan:

..."Idak ado mbak nyo ngingatin, nyo tu sibuk..."

...(tidak ada mbak dia mengingatkan, dianya sibuk) (Inf 3)

..."Iya selalu diingatkan. Lumayan sering lah yah, ada kali 3 sampai 4 kali. Kalo dari suami sih katanya kalo bisa ASI eksklusif biar bayinya lebih sehat lebih kuat..."(Inf 4)

Hasil penelitian juga menunjukkan bahwa informan dengan efikasi rendah tidak mendapatkan dukungan penilaian dan instrumental dari suaminya sedangkan informan dengan efikasi rendah mendapatkan dukungan penilaian dan instrumental dari suaminya. Berikut kutipan wawancara oleh informan dukungan penilaian:

..."Idak ado mbak. idak pernah nyo muji. Paling nyo Cuma ngingati ajo. Anak la dikasih asi apo belum. Idak tau nyo apo itu ASI apo itu susu botol..."

...(tidak ada mbak. Idak pernah dia muji. Paling dia Cuma ngingatkan saja. Anak sudah dikasi ASI apa belum. Tidak tahu dia apa itu ASI atau susu botol) (Inf 3$)$

..."Ado. Sering. Keceknyo wai pintar nian bunda ko. Tengok gibran ajo sampai tidur pulas cak iko..."

...(ada. Sering. Katanya wih pintar sekali bunda ini. Lihat Gibran aja sampai tidur pulas seperti ini) (Inf 5) Berikutkutipanwawancaradukungani nstrumental :

...."Cuman kalo laki ngasih duit ajo cak itu na untuk beli makan kan, untuk beli sayur belanjo. Kalo saran tuh paling nyo suruh suruh beli sayur beli buah cak itu..."

...( Cuma kalau suami ngasih duit saja seperti itu untuk membeli 
makanan, untuk membeli sayur belanja. Kalau saran sih paling menyuruh membeli sayur, membeli buah seperti itu) (inf 2)

..."Pernah dari pas hamil sering laki ayuk tu masak untuk ayuk. Hobby masak. Sayur, ikan pokoknya yang bagus untuk ASI kecek laki ayuk..."

...(Pernah dari waktu hamil sering suami mbak itu masak untuk mbak. Hobby masak, sayur, ikan pokoknya yang bagus untuk ASI kata suami mbak) (Inf 4)

\section{Dukungan Kader}

Hasil penelitian menunjukkan bahwa informan dengan efikasi diri menyusui tinggi maupun rendah hanya mendapatkan dukungan informasional saja dari kader. Berikut kutipan wawancara dengan informan :

..."Kader maren cuma ngasih tau tetang ASI ajo..."

...(Kader kemarin hanya memberi tahu saja tentang ASI) (Inf 5)

\section{Dukungan Tenaga Kesehatan (bidan)}

Hasil penelitian menunjukkan bahwa informan dengan efikasi tinggi dan efikasi rendah mendapatkan dukungan informasional, emosional, penilaian dan instrumental dari tenaga kesehatan (bidan). Berikut kutipan wawancara dengan informan :

..."Ado galak bidan ngasih tau jugo. Waktu perikso hamil ngasih tau, waktu dem melahirkan tu langsung kasih tau jugo..."

...(Ada sering bidan memberi tahu juga. Sewaktu periksa hamil bidan memberi tahu, waktu sudah melahirkan juga langsung dikasih tahu) (Inf 2)

..."Kalo bidan nyo galak ngingatkan galak ngomong, bidan tu lah yg galak ngingatkan..."

...(Kalau bidannya sering ngingatkan sering ngomong, bidan itu saja yang sering mengingatkan) $(\operatorname{Inf} 2)$
..."Bidan pas lahiran marenkan bayinyo kan adek tu kan disusui tu, bidan nengok. Kecek bidan ai pintar nian adek nyo. Kelak pas nyusi harus cak itu..."

...(Bidan waktu lahiran kemarinkan bayinyakan adeknya itu kan disusui tu, bidan lihat, kata bidan ai pintar sekali adeknya. Nanti pas nyusui harus seperti ini) (Inf 5)

..."Kalo bidan pas lahiran kemarin ado. Ngasih nasi kek sayur mbak, sayur katu..."

...(Kalau bidan waktu lahiran kemarin ada. Memberi nasi sama sayur mbak, sayur katu) (Inf 3)

\section{PEMBAHASAN}

1. Dukungan Keluarga (suami)

Hasil penelitian menunjukkan bahwa ibu yang memiliki efikasi rendah hanya mendapatkan dukungan emosional saja dari suami sedangkan ibu yang memiliki efikasi tinggi mendapatkan dukungan informasional, emosional, penilaian, dan instrumental dari suami. Dukungan informasi yang diberikan oleh suami sangat berguna untuk meningkatkan efikasi ibu menyusui. Dengan informasi yang diberikan bisa memberikan arahan kepada ibu untuk bertindak apalagi jika arahan itu langsung dari suami sehingga semakin meningkatkan efikasi diri ibu menyusui untuk memberikan ASI Eksklusif. Dukungan emosional yang diberikan oleh suami membuat ibu merasa diperhatikan oleh suaminya sehingga menyebabkan ibu merasa nyaman, tentram, merasa dicintai dan di hargai.

Dukungan penilaian dan instrumental yang diberikan oleh suami membuat ibu semakin terdorong untuk memberikan ASI Eksklusif kepada bayinya sehingga semakin meningkatkan rasa percaya diri ibu untuk memberikan ASI Eksklusif 
kepada bayinya dan juga merasa berharga dimata suaminya.

Hasil penelitian ini sejalan dengan penelitian yang dilakukan oleh Komalasari (2016) yang mengatakan pada dimensi dukungan, lebih dari setengah responden memiliki tingkat selfefficacy yang tinggi. Tinginya selfefficacy pada dimensi ini disebabkan oleh dukungan emosional dan fisik yang sudah ibu dapatkan dari suami (mean= $3,13)$ dan keluarga $($ mean $=3,20)$ sudah optimal.

Hal ini sejalan dengan penelitian Arifiati (2017) yang menyatakan kurangnya dukungan dari keluarga terutama dukungan dari ayah bayi dan orang tua mengakibatkan bayi tidak mendapatkan ASI eksklusif. Untuk bisa memberikan ASI secara eksklusif, seorang ibu harus mendapatkan dukungan dari berbagai pihak. Pihak keluarga dalam hal ini suami, memegang peranan penting dalam mendukung istri untuk menyusui eksklusif dan ayah merupakan bagian yang vital dalam keberhasilan atau kegagalan menyusui.

\section{Dukungan Kader}

Hasil penelitian menunjukkan bahwa informan dengan efikasi diri menyusui tinggi maupun rendah hanya mendapatkan dukungan informasional saja dari kader. Jika ibu mendapatkan dukungan dari kader maka efikasi diri menyusui pada ibu akan semakin meningkat karena semakin banyak dukungan sosial yang ibu dapatkan maka dorongan untuk memberikan ASI Eksklusif akan semakin besar sehingga meningkatkan rasa keyakinan yang tinggi pada ibu untuk selalu memberikan ASI Eksklusif.

Menurut Amirudin

keberhasilan pemberian ASI eksklusif dipengaruhi oleh adanya dukungan kader kesehatan dikarenakan kader kesehatan memiliki peranan dalam menyukseskan program ASI eksklusif.Kader kesehatan merupakan salah satu kelompok pendukung ASI yang ada di masyarakat, wujud kegiatan yang dilakukan adalah bersifat promotive dan preventif (Arifin, 2015).

\section{Dukungan Tenaga Kesehatan (bidan)}

Hasil penelitian menunjukkan bahwa informan dengan efikasi tinggi dan efikasi rendah mendapatkan dukungan informasional, emosional, penilaian dan instrumental dari tenaga kesehatan (bidan). Semakin banyak informasi yang informan terima maka semakin tinggi efikasi diri menyusui untuk memberikan bayinya ASI Eksklusif. Dukungan penilaian yang diberikan oleh bidan membuat informan merasa usahanya dihargai dan tidak sia-sia sehingga keinginan untuk memberikan ASI Eksklusif pun semakin meningkat. Dukungan yang diberikan oleh bidan mampu meningkatkan motivasi ibu untuk memberikan ASI Eksklusif kepada bayinya hal ini dikarenakan ibu merasa senang dengan adanya dukungan tersebut.

Penelitian ini sejalan dengan penelitian yang dilakukan oleh Josefa (2011) yang menyatakan bahwa peran tenaga kesehatan sangat penting untuk mendukung ibu tetap menyusui. Tidak hanya dengan memberikan obat atau menyarankan makanan tertentu, tetapi yang lebih penting adalah menjelaskan kepada ibu-ibu bahwa dengan rangsangan isapan bayi terusmenerusakan memacu produksi ASI lebih lagi.

\section{KESIMPULAN}

Dukungan yang paling banyak yang diterima oleh ibu nifas adalah dukungan yang diberikan oleh tenaga kesehatan (bidan) dan paling banyak berupa dukungan informasional.

Kepada pihak Puskesmas diharapkan dapat memberikan penyuluhan tentang ASI 
Eksklusif secara menyeluruh, mengadakan penyuluhan rutin, serta membuat kebijakan-kebijakan tentang peningkatan pemberian ASI Eksklusif. Penyuluhan tidak hanya diberikan kepada ibu hamil dan menyusui tapi sebaiknya suami ibu hamil dan kader juga dilibatkan. Kader juga sebaiknya di latih dan diadakan penyegaran kader agar kader mengetahui apa saja tugas dan perannya dalam meningkatkan keberhasilan ibu nifas untuk menyusui bayi nya secara ekslusif. Bagi respon dan diharapkan dapat lebih

\section{DAFTAR RUJUKAN}

Amirudin.2009. Pengaruh Motivasi terhadap Kinerja Konselor ASI Ekslusif di Kabupaten Aceh Barat Provinsi Nanggroe Aceh Darusalam Tahun 2008.Tesis.Universitas Sumatera Utara Medan.

Arifiati, Nurce. 2017. Analisisi Faktor yang Mempengaruhi Pemberian ASI Ekslusif pada Bayi di Kelurahan Warnasari Kecamatan Citangkil Kota Cilegon. Prosiding Seminar Nasional IKAKESMADA "Peran Tenaga Kesehtan dalm Pelaksanaan SDGs" ISBN: 978-979-3812-41-0.

Denis. 2011. A Pilot Randomized Controlled Trial Of A Breastfeeding Self Efficacy Intervention With Primiparous Mothers. Journal of Obstetric Gynecologic and Neonatal Nursing 40 (2): 35-46

Dinas Kesehatan. 2015. Profil Dinas Kesehatan Provinsi Bengkulu.Dinkes Provinsi Bengkulu.

Febriana, Nur 'Aini, Wiwin Lismidiati, dan Heny Suseani Pangastuti. 2014. Faktor-faktor yang Berhubungan dengan Self-Efficacy Menyusui di Ruang Bougenville 2 RSUP dr. Sardjito Yogyakarta. Sripsi. Universitas Gadjah Mada Yogyakarta Program Studi Keperawatan.

Feni. 2017. Faktor-faktor yang Berhubungan dengan Efikasi Diri Menyusui pada Ibu Hamil TM III di Kota Bengkulu tahun 2017. Skripsi.Politeknik Kementerian Kesehatan meningkatkan efikasi diri, pengetahuan serta motivasi dalam memberikan ASI Eksklusif dengan mengikuti penyuluhanpenyuluhan serta mencari informasi mengenai ASI Eksklusif dari media massa maupun media cetak dan elektronik. Bagi penelitilain diharapkan dapat mengembangkan penelitian ini dengan variabel, desain dan sampel yang berbeda yang berhubungan dengan dukungan sosial tentang efikasi diri menyusui pada ibu nifas.

Republik Indonesia Jurusan Kebidanan Program Studi Diploma IV Kebidanan.

Ghufron, M.N. danRisnawita. 2010. Teori- Teori Psikologi. Yogyakarta: Ar-Ruzz Media.

Khoiriyah, Annisaul. 2014. Hubungan Antara Efikasi Diri dan Dukungan Suami dalam Menyusui dengan Pemberian ASI Ekslusif pada Ibu Menyusui di Wilayah Kerja Puskesmas Urangagung Sidoarjo. Tesis. Universitas Sebelas Maret Surakarta Program Studi Kedokteran Keluarga.

Komalasari, Masriyah, Tetti Solehati, dan Efri Widianti. 2016. Gambaran Tingkat SelfEfficacy Ibu Post Seksio Sesarea saat Menyusui di RSKIA Kota Bandung. Jurnal Pendidikan Keperawatan Indonesia. 2(2):95-103

Muaningsih.2013. Studi Komparasi antara Breastfeeding Self-Efficacy pada Ibu Menyusui di RSSIB dengan Non-RSSIB dan Faktor Yang Mempengaruhinya. Thesis.Universitas Indonesia.

Pakseresht, Sedigheh, Zahra B Khalesi, and EhsanKazem.2017. Comparing maternal breastfeeding self-efficacy during first week and sixth week postpartum. Electronic Physician 9(2): 3751-3755.

Wardani. 2012. Pengaruh Pelatihan Komunikasi Efektif Untuk Meningkatkan Efikasi Diri Mahasiswa. Jurnal Psikologi Pendidikan dan Perkembangan 1(2):1-7 